\begin{tabular}{|c|} 
Jurnal Keolahragaan \\
Volume 4 - Nomor 2, September 2016, (155- 163) \\
Tersedia online: http://journal.uny.ac.id/index.php/jolahraga
\end{tabular}

\title{
KONTRIBUSI FISIK DAN TEKNIK TERHADAP KETERAMPILAN DRIBBLING ATLET BOLABASKET PUTRI JUNIOR KABUPATEN GUNUNGKIDUL
}

\author{
Chrisssandy Yudha Pratama ${ }^{1} *$, Panggung Sutapa ${ }^{2}$ \\ ${ }^{12}$ Program Studi Ilmu Keolahragaan, Program Pascasarjana, Universitas Negeri Yogyakarta. Jalan \\ Colombo No 1, Karangmalang, Yogyakarta 55281, Indonesia \\ * Korespondensi Penulis. Email: chrissandy_06@gmail.com
}

Received: 3 March 2016; Revised: 22 November 2016; Accepted: 22 November 2016

\begin{abstract}
Abstrak
Penelitian ini bertujuan untuk mengetahui kontribusi kondisi fisik dan teknik terhadap keterampilan menggiring bola (dribbling) atlet bolabasket putri junior di Kabupaten Gunungkidul. Penelitian ini menggunakan metode Partial least Square (PLS). Data dikumpulkan menggunakan tes pengukuran dan rubrik. Tes pengukuran digunakan untuk mengukur faktor kondisi fisik yang terdiri atas 6 item dan tes keterampilan dribbling, kemudian rubrik digunakan untuk mengukur penilaian teknik. Teknik analisis data penelitian ini menggunakan ANAVA. Uji prasyarat analisis data menggunakan uji normalitas, uji linieritas dan uji multikolinieritas yang menggunakan program SMART PLS. Hasil penelitian adalah sebagai berikut: (1) kontribusi faktor fisik terhadap dribbling atlet bolabasket putri junior Gunungkidul sebesar 21\%, (2) kontribusi faktor teknik terhadap dribbling atlet bolabasket putri junior Gunungkidul sebesar 55\%, dan (3) kontribusi kondisi fisik dan teknik terhadap dribbling atlet bolabasket putri junior Gunungkidul sebesar 45,5\%.
\end{abstract}

Kata Kunci: faktor kondisi fisik, teknik, dribbling, bolabasket.

\section{THE CONTRIBUTION OF PHYSICAL AND TECHNIQUES TO THE DRIBBLING SKILLS OF JUNIOR WOMAN BASKETBALL ATHLETES IN GUNUNGKIDUL}

\begin{abstract}
This research aims to find out the contribution of physical condition and techniques to the dribbling skills of junior woman basketball athletes in Gunungkidul. This research was used the Partial least Square (PLS) method. Measurement test was used to measure the physical condition factor consisting of 6 items and dribbling skills, then the rubric was used to measure techniques. The data analysis techniques used ANOVA. Prerequisite test data analysis used normality test, linearity and multicollinearity test that used SMART PLS program. The results of the research show that: (1) the contribution of the physical factors to the dribbling skills of junior woman basketball athletes in Gunungkidul is 0.210 at $21 \%$, (2) the contribution of the technical factors to the dribbling skills of junior woman basketball athletes in Gunungkidul is 0.550 at 55\%, and (3) the contribution of the physical condition factors and technique to the dribbling skills of junior woman basketball athletes in Gunungkidul is 0.455 at $45.5 \%$.
\end{abstract}

Keywords: factors of physical condition, technique, dribbling, basketball.

How to Cite: Pratama, C., \& Sutopo, P. (2016). Kontribusi fisik dan teknik terhadap keterampilan dribbling atlet bolabasket putri junior Kabupaten Gunungkidul. Jurnal Keolahragaan, 4(2), 155 - 163. doi:http://dx.doi.org/10.21831/jk.v4i2.8885

Permalink/DOI: http://dx.doi.org/10.21831/jk.v4i2.8885 


\section{PENDAHULUAN}

Bolabasket merupakan cabang olahraga berbentuk permainan yang mempunyai tujuan memasukkan bola sebanyak mungkin ke keranjang lawan, serta mencegah agar lawan tidak dapat menciptakan nilai dengan cara lempar tangkap (passing), menggiring bola (dribbling), dan menembak (shooting). Secara umum, Ahmadi (2007; pp. 13-21) menyebutkan bahwa keterampilan teknik dasar dari permainan bolabasket adalah mengoperkan bola, menerima bola, menggiring bola, menembak, olah kaki, pivot. Pada prinsipnya olahraga permainan bolabasket adalah salah satu dari permainan invasi yaitu permainan yang saling menyerang untuk memasukkan bola ke tujuannya yaitu ring basket. Permainan bolabasket dimainkan oleh 2 tim yang masing-masing terdiri atas 5 orang dalam setiap tim. Pemenang dalam olahraga permainan ini ditentukan dari perolehan point terbanyak. Luas lapangan dalam permainan ini adalah $28 \mathrm{~m} \times 15 \mathrm{~m}$, yang dapat terbuat dari ubin, lantai, serta papan. Lama permainan ini adalah $4 \times 10$ menit.

Faktor untuk meningkatkan kemampuan dasar sebagai seorang pemain basket adalah kemampuan koordinasi gerak fisik, taktik dan mental. Pada bolabasket, semakin baik seorang pemain dapat memiliki keterampilan teknik dasar bolabasket, dalam hal ini khususnya dribbling, semakin baik kemungkinan untuk sukses. Seperti yang dikemukakan oleh Nurhidayah \& Sukoco (2015), bahwa pada hakikatnya olahraga bolabasket adalah olahraga yang membutuhkan keterampilan tinggi. Kemampu-an dribble untuk melakukan ball handling saat ini bukanlah hanya sebagai pelengkap saja dalam permainan bolabasket. Kemampuan melakukan dribble juga berpengaruh pada kemampuan tim bolabasket dalam melakukan penyerangan.

Dahulu banyak orang berpikir bahwa bermain bolabasket tidak perlu melakukan dribble, karena dirasa cukup hanya menggunakan passing dan shooting saja. Namun pendapat tersebut mulai memudar seiring dengan perkembangan permainan bolabasket yang sangat cepat. Menurut Oliver (2007, p. 49), mendribble adalah salah satu dasar bolabasket yang pertama harus diperkenalkan kepada pemula, karena keterampilan ini sangat penting bagi setiap pemain yang terlibat dalam pertandingan bolabasket. Sejalan dengan pendapat tersebut, Prusak (2007, p. 25) berpendapat, beragam kontrol dan olah bola sangat dibutuhkan karena bolabasket adalah olahraga yang bersifat sangat dinamis, danselalu berubah.

Di era modern ini, bolabasket telah menjelma menjadi permainan yang lebih menghibur daripada hanya sekedar mencetak angka saja. Bahkan tidak hanya pada pertandingan bolabasket putra, putri pun juga demikian. Menurut James \& Ridinger (2002), tidak terdapat perbedaan yang signifikan antara permainan bolabasket putra dengan putri. Pada era ini, semua tim baik putra dan putri percaya bahwa evaluasi tentang semua kemampuan teknik dasar berguna untuk kesuksesan sebuah tim menjadi lebih baik (Martinez \& Martinez, 2011). Anggapan bahwa bermain bolabasket dapat hanya menggunakan teknik passing dan shooting pun saja kini telah hilang karena dirasa belum cukup.

Gunungkidul merupakan salah satu kabupaten di Provinsi DIY. Berdasarkan pengalaman, observasi, dan pengamatan terhadap kegiatan bolabasket di daerah ini, hampir di setiap kecamatan di Gunungkidul memiliki club bolabasket, semua berjumlah 18 club yang secara resmi terdaftar di Pengcab PERBASI Kabupaten Gunungkidul. Minat untuk mengikuti latihan bolabasket disana juga cukup tinggi, baik putra maupun putri, terbukti dari jumlah pemain yang terdaftar dalam tiap club tersebut.

Pada setiap club disana, yang dilatih adalah berbagai hal tentang bolabasket, dari mulai teknik dasar, taktik dan mental.Selain itu, para atlet bolabasket junior Gunungkidul juga sering diikut sertakan oleh Pengurus Cabang PERBASI Gunungkidul dalam turnamen bolabasket Kelompok Umur seperti Kejuaraan Tingkat Kabupaten dan Kejuaraan Tingkat Provinsi. Pada kesempatan Kejuaraan Tingkat Kabupaten Tahun 2014 tersebut, pemenang untuk kategori putri dan putra Kelompok Umur 16 tahun adalah club ASRI dari Wonosari, sedangkan untuk kategori putri Kelompok Umur 18 dimenangkan oleh club CNB dari Piyaman dan putra dimenangkan oleh club ASRI dari Wonosari. Namun, berdasarkan observasi peneliti pada ajang Kelompok Umur tersebut, pada saat kegiatan pertandingan bolabasket yang dilakukan, ternyata para pemain CNB putri yang menjadi juara pada Turnamen Kelompok Umur 18 tahun tersebut kurang menguasai teknik dasar bermain bolabasket, terlebih pada saat dribbling, masih banyak yang dribbling-nya kurang baik, meskipun kondisi fisik mereka terlihat baik, 


\section{Jurnal Keolahragaan 4 (2), September 2016 - 157}

Chrissandy Yudha Pratama, Panggung Sutapa

hingga akhirnya banyak bola yang di steal oleh lawan.Untuk tim ASRI putri yang menjadi pemenang pada Kelompok Umur 16 tahun, meskipun keluar sebagai pemenang dengaan teknik yang baik, namun ternyatajuga kurang menguasai kemampuan dribbling, terlihat teknik ballhandling yang dipakai kurang baik karena daya tahan otot lengan mereka terlihat sangat lemahsaat melakukan dribbling sehingga bola banyak yang terlepas dari penguasaan.

Walaupun pada kenyataannya kondisi fisik yang baik pada pelaksanaan dribbling belum tentu membuat kemampuan dribbling meningkat tanpa diimbangi dengan latihan teknik yang benar. Tetapi kondisi fisik yang baik tidak dapat diabaikan sebagai faktor penentu terlaksananya kemampuan dribbling yang baik. Sehingga dari anggapan-anggapan tersebut di atas berkenaan dengan kemampuan dribbling dapat disimpulkan bahwa dalam keberhasilan atau pencapaian prestasi dribbling terdapat faktor lain yang juga mempengaruhi. Lebih lanjut Sukadiyanto (2005, p. 14) berpendapat bahwa sasaran dan tujuan latihan untuk pencapaian penampilan secara garis besar antara lain; (a) meningkatkan dan mengembangkan kualitas fisik umum dan khusus, (b) menambah dan menyempurnakan teknik, (c) mengembangkan dan menyempurnakan taktik dan strategi, dan (d) meningkatkan kualitas dan kemampuan psikis.

Secara sekilas gerakan dribbling terlihat sebagai keterampilan yang sederhana dan mudah dilakukan, tapi jika dikaji secara lebih mendalam, keterampilan dribbling cukup rumit untuk dilakukan, dan hal ini membutuhkan faktor kondisi fisik yang baik. Sama seperti yang disampaikan oleh Fresno (2012), "in addition, the knowledge of body composition and fitness level of the players and their evolution through the season is very helpful for the Head Coach, ...". Seberapa besar dan seberapa banyak keterkaitan dari pengaruh tersebut belum dapat diketahui dengan pasti. Padahal dalam suatu kompetisi, aspek fisik dan fisiologi seperti itu sangat diperlukan dalam suatu pelatihan bolabasket (Montgomery, Pyne, \& Minahan, 2012).

Faktor teknik merupakan cara yang paling efektif, efisien, dan sederhana untuk memecahkan masalah yang dihadapi dalam pertandingan dan dibenarkan oleh peraturan. Seperti anggapan-anggapan mengenai dribbling, bahwa penggunaan teknik yang benar tidak bisa diabaikan sebagai faktor penentu dalam kemampuan men-dribble. Atas dasar itulah maka peneliti berusaha meneliti tentang keterampilan dribbling yang dihubungkan dengan kondisi fisik dan teknik. Penggunaan teknik dribble yang baik tentunya harus memperhatikan sikap-sikap dasar dribble yang baik pula. Dribble pada olahraga bolabasket termasuk dalam aktivitas gerak. Dari pernyataan tersebut apabila di implikasikan ke dalam Bompa (2009, p. 78) yang menyatakan bahwa semua aktivitas gerak dalam olahraga selalu mengundang unsur-unsur kekuatan, kecepatan, durasi yang merupakan penjabaran dari unsur fisik, sehingga hal tersebut mengasumsikan bahwa dalam penguasaan teknik yang baik akan selalu berhubungan dengan kapasitas fisik. Karena fisik merupakan sarana pendukung utama dalam rangka merealisasikan gerakan teknik.

Berdasarkan latar belakang tersebut maka akan dilakukan penelitian mengenai prestasi dribbling yaitu membahas tentang analisis konstribusi faktor fisik dan teknik terhadap kemampuan dribbling. Dilakukannya penelitian kontribusi kondisi fisik dan teknik terhadap keterampilan dribbling atlet bolabasket putri junior di Kabupaten Gunungkidul, pelatih atlet bolabasket putri junior di Kabupaten Gunungkidul dapat melihat seberapa kemampuan teknik dasar pemainnya didalam bermain bolabasket khususnya pada teknik dasar dribbling dan pengaruh kondisi fisik dan teknik terhadap dribbling atlet bolabasket putri junior di Kabupaten Gunungkidul.

Penelitian ini bertujuan untuk mengetahui; (1) kontribusi faktor kondisi fisik terhadap keterampilan dribbling atlet bolabasket putri junior di Kabupaten Gunungkidul; (2) kontribusi faktor teknik terhadap keterampilan dribbling atlet bolabasket putri junior di Kabupaten Gunungkidul; (3) kontribusi faktor kondisi fisik dan teknik terhadap keterampilan dribbling atlet bolabasket putri junior di Kabupaten Gunungkidul.

Diketahuinya kontribusi kondisi fisik dan teknik terhadap keterampilan dribbling atlet bolabasket putri junior di Kabupaten Gunungkidul, maka penelitian ini bermanfaat; (1) secara teoritis memperkaya penelitian yang telah ada di bidang olahraga, sehingga dapat digunakan sebagai wahana dalam pembinaan prestasi olahraga khususnya cabang olahraga bolabasket di Gunungkidul; (2) secara praktis sebagai informasi kepada pihak yang berkepentingan dalam usaha meningkatkan prestasi olahraga 


\section{Jurnal Keolahragaan 4 (2), September 2016 - 158}

Chrissandy Yudha Pratama, Panggung Sutapa

khususnya bolabasket di Gunungkidul. Bagi pendidik atau pelatih berguna sebagai bahan pembelajaran agar dalam memberikan program latihanyang memperhatikan faktor-faktor pendukung dalam meningkatkan prestasi khususnya dalam keterampilan dribbling dan bagi pemain bolabasket agar dapat meningkat-kan kondisi fisikdanteknik yang mendukung dalam melakukan dribbling bolabasket.

\section{METODE}

Penelitian ini menggunakan pendekatan kuantitatif. Inti dari penelitian kuantitatif adalah bahwa penelitian menguji teori dengan menggunakan model konseptual. Penelitian kuantitatif harus seobjektif mungkin mengenai penelitian yang perlu dilakukan dalam rangka berusaha memaksimalkan objektivitas (Jonker \& Wahyuni, 2011, p. 69). Adapun desain dalam penelitian ini adalah non eksperimental yang berarti tidak terdapat perlakuan apapun yang diberikan kepada subjek penelitian yang memungkinkan timbulnya dampak khusus pada variabel-variabel terukur. Metode yang digunakan dalam penelitian ini adalah korelasional dan regresio-nal yaitu penelitian yang bertujuan mencari tata hubungan logik antara variabel bebas dan variabel terikat. Variabel yang terlibat tidak saja variabel yang secara langsung dapat diukur tetapi juga variabel-variabel yang bersifat latent, dimana yang dapat diamati dan diukur hanya indikator-indikatornya saja. Metode struktural dalam penelitian ini melibatkan dua variabel independen (faktor kondisi fisik dan teknik), serta satu variabel dependen (keteram-pilan dribbling). Enam variabel indikator yang terdapat pada faktor kondisi fisik (daya tahan otot lengan, kelincahan, power otot tungkai, kecepatan lari, kelentukan, dan keseimbangan tubuh), dua indikator yang terdapat pada faktor teknik (fase persiapan dan fase pelaksanaan).

Penelitian ini dilaksanakan pada bulan Maret 2016. Tempat penelitian ini dilakukan di SMA N 2 Wonosari yang beralamat di Jl. Ki Ageng Giring no 3, Kepek, Wonosari, Gunungkidul. SMA N 2 Wonosari berbatasan dengan Balai Desa Kepek, Wonosari, Gunungkidul.

Proses pengambilan sampel atau subjek dalam penelitian ini diawali dengan kegiatan observasi terhadap atlet bolabasket putri junior Kabupaten Gunungkidul dari masing-masingmasing club di Kabupaten Gunungkidul. Langkah selanjutnya adalah memilih atlet secara acak atau random. Teknik sampling dalam penelitian ini adalah menggunakan simple random sampling. Teknisnya dengan cara mengundi daftar nama atlet yang di dapatkan oleh peneliti melalui kegiatan observasi. Hasil pemilihan secara acak diperoleh sampel penelitian dengan jumlah total subjek adalah 100 subjek.

\section{Prosedur}

Prosedur diawali dengan memvalidasi instrumen yang akan digunakan, memvalidasi alat ukur, mememinta perizinan, untuk kemudian melakukan proses pengambilan data penelitian. Data yang diperoleh kemudian dianalisis. Analisis data menggunakan bantuan program SMART PLS.

\section{Data, Intrumen, dan Teknik Pengumpulan Data}

Data pada penelitian ini adalah hasil tes pengukuran dan rubrik dari subjek yang telah ditentukan. Teknik pengumpulan data dalam penelitian ini adalah menggunakan teknik tes dan pengukuran untuk mengukur faktor kondisi fisik dan keterampilan dribbling, kemudian rubrik untuk mengetahui faktor teknik. Untuk memperoleh data daya tahan otot lengan diukur dengan tes push up. Untuk memperoleh data kelincahan diukur dengan tes kelincahan Dogging Run. Untuk memperoleh data power otot tungkai diukur dengan menggunakan Vertical Jump Test, satuan yang digunakan adalah centimeter. Pengukuran agar diperoleh data mengenai kecepatan lari menggunakan tes lari cepat 20 meter. Pengukuran kelentukan dalam penelitian ini dengan Standing Trunk Flexion yang diukur dengan balok/mistar 50 $\mathrm{cm}$. Pengukuran kelentukan dalam penelitian ini dengan Standing Balance Test yang diukur dengan alat stopwatch.

Untuk mengukur kontribusi faktor teknik dalam penelitian ini menggunakan 10 kriteria penilaian gerakan dalam melakukan dribble yang sebelumnya sudah dilakukan expert judgement pada para ahli bolabasket, yaitu; (1) posisi tangan memegang bola, (2) posisi kaki, (3) posisi badan, (4) pantulan bola pada awal gerakan, (5) gerakan lengan awal, (6) gerakan pergelangan tangan ketika sudah memantulkan bola, (7) ritme pantulan saat masih posisi diam, (8) ritme pantulan saat merubah arah, (9) posisi arah penglihatan mata, (10) posisi tubuh ketika membawa bola pada saat merubah arah dan kecepatan. Kesepuluh kriteria penilaian tersebut oleh para pelatih bolabasket dibagi menjadi dua 
fase, yaitu fase persiapan (kriteria 1 sampai 5) dan fase pelaksanaan (kriteria 6 sampai 10). Instrumen untuk mengevaluasi teknik dribbling yang dimiliki oleh atlet yaitu dengan menggunakan rubrik penilaian.

Instrumen yang digunakan peneliti untuk memperoleh hasil pengukuran dribbling adalah dengan mengukur kemampuan teknik menggiring bola melewati rintangan yang disiapkan, diukur dengan stopwatch, yang mengadopsi dari pengukuran keterampilan menggiring bolabasket dari STO.

\section{Teknik Analisis Data.}

Dalam penelitian ini analisis data yang digunakan adalah dua macam yaitu analisis data deskriptif dan analisis data dengan metode PLS. Analisis deskriptif dilakukan dengan menggunakan program SPSS. Penelitian ini menggunakan metode analisis data dengan menggunakan software Smart PLS versi 2.0.m. PLS (Partial Least Square) merupakan analisis persamaan struktural (SEM) berbasis varian yang secara simultan dapat melakukan pengujian model pengukuran sekaligus pengujian model struktural. Model pengukuran digunakan untuk uji validitas dan reabilitas, sedangkan model struktural digunakan untuk uji kausalitas (pengujian hipotesis dengan model prediksi). Lebih lanjut Yamin \& Kurniawan (2011, p. 12) menjelaskan bahwa PLS adalah metode analisis yang power full, karena dapat digunakan pada setiap jenis skala data (nominal, ordinal, interval, dan rasio), tidak mengasumsikan data harus dengan pengukuran skala tertentu. Menurut Ghazali (2012, p. 77) pengolahan data SEM berbasis PLS memerlukan 2 tahap untuk menilai Fit Model dari sebuah model penelitian yaitu menilai outer model atau measurement model dan evaluasi terhadap inner model.

\section{HASIL DAN PEMBAHASAN}

Hasil analisis yang digunakan adalah hasil analisis normalitas. Hasil analisis menunjukkan bahwa distribusi variabel penelitian normal, jika nilai signifikansi > 0.05. Hasil menunjukkan bahwa ketiga variabel penelitian memperoleh signifikansi 0.00000 . Ini berarti ketiga variabel tersebut dinyatakan tidak normal. Ringkasan hasil analisis disajikan dalam Tabel 1.
Tabel 1. Ringkasan Hasil Uji Normalitas Data (Multivariate Normality).

\begin{tabular}{llll}
\hline No & Variabel & Signifikansi & Kesimpulan \\
\hline 1 & Fisik & 0.000 & Tidak normal \\
2 & Teknik & 0.009 & Tidak normal \\
3 & Dribling & 0.017 & Tidak normal \\
\hline
\end{tabular}

Uji linearitas menggunakan program SPSS versi 20. Hasil analisis menunjukkan bahwa hubungan antar variabel laten dinyatakan oleh nilai $\mathrm{p}$ kurang 0.05 ini berarti hubungan antar variabel laten dinyatakan linear. Ringkasan hasil analisis disajikan oleh Tabel 2.

Tabel 2. Ringkasan Hasil Uji Linearitas Hubungan

\begin{tabular}{lllll}
\hline \multirow{2}{*}{ No } & Variabel & \multicolumn{2}{c}{ Linearity } & \\
\cline { 3 - 4 } & & F & P & Kesimpulan \\
\hline 1 & Fisik-dribble & 30.019 & $0.000<0.05$ & Linear \\
2 & Teknik-dribble & 80.300 & $0.000<0.05$ & Linear \\
\hline
\end{tabular}

Uji multikolilinieritas menggunakan program SPSS versi 20. Ringkasan hasil analisis disajikan oleh Tabel 3.

Tabel 3. Ringkasan hasil uji multikolilinearitas

\begin{tabular}{|c|c|c|c|}
\hline \multicolumn{4}{|c|}{ Coefficients $^{\mathrm{a}}$} \\
\hline & \multirow{2}{*}{ Model } & \multicolumn{2}{|c|}{ Collinearity Statistics } \\
\hline & & Tolerance & VIF \\
\hline \multirow{3}{*}{1} & (Constant) & & \\
\hline & $\mathrm{X} 1$ & & 1.264 \\
\hline & $\mathrm{X} 2$ & & 1.264 \\
\hline
\end{tabular}

Validitas konvergen adalah nilai loadong faktor pada variabel laten dengan indikator. Nilai faktor loading diharapkan $>0.7$, tetapi nilai antara 0.5-0.6 masih bisa ditolerir selama model masih dalam tahap pengembangan. Dari hasil output terlihat nilai validitas konvergen paling kecil pada indikator X1.1 (0.730) sedangkan yang paling tinggi pada indikator Y (1.000).

Tabel 4. Hasil Uji Validitas Konvergen

\begin{tabular}{cccc}
\hline Indikator & Dribble & Fisik & Teknik \\
\hline X1.1 & & 0.730 & \\
X1.2 & & 0.757 & \\
X1.3 & & 0.784 & \\
X1.4 & & 0.854 & \\
X1.5 & & 0.869 & \\
X1.6 & & 0.902 & \\
X2.1 & & & 0.919 \\
X2.2 & & & 0.907 \\
Y1 & 1.000 & & \\
\hline
\end{tabular}




\section{Jurnal Keolahragaan 4 (2), September 2016 - 160}

Chrissandy Yudha Pratama, Panggung Sutapa

Validitas diskriminan ini melihat nilai cross loading faktor. Cross loading faktor berguna untuk melihat apakah kontruk memiliki diskriminan yang memadai yaitu dengan cara membandingkan korelasi indikator dengan kontruknya harus lebih besar dibandingkan korelasi antara indikator dengan kontruk yang lain. Jika korelasi indikator kontruk memiliki nilai lebih tinggi dibandingkan dengan korelasi indokator tersebut terhadap kontruk lain, maka dikatakan konstruk tersebut memiliki Validitas diskriminan yang tinggi. Nilai cross loading dapat dilihat pada Tabel 5:

Tabel 5. Hasil Uji Validitas Diskriminan

\begin{tabular}{cccc}
\hline Indikator & Dribble & Fisik & Teknik \\
\hline X1.1 & & 0.730 & \\
X1.2 & & 0.757 & \\
X1.3 & & 0.784 & \\
X1.4 & & 0.854 & \\
X1.5 & & 0.869 & \\
X1.6 & & 0.902 & \\
X2.1 & & & 0.919 \\
X2.2 & & & 0.907 \\
Y1 & 1.000 & & \\
\hline
\end{tabular}

Uji reliabilitas menggunakan program SPSS versi 20. Ringkasan hasil analisis disajikan oleh Tabel 6, 7 dan 8, sedangkan tabel analisisnya selengkapnya disajikan pada lampiran.

Tabel 6. Hasil Uji Reliabilitas untuk Variabel 1 (Fisik)

\begin{tabular}{ccc}
\hline \multicolumn{3}{c}{ Reliability Statistics } \\
\hline $\begin{array}{c}\text { Cronbach's } \\
\text { Alpha }\end{array}$ & $\begin{array}{c}\text { Cronbach's Alpha Based } \\
\text { on Standardized Items }\end{array}$ & $\begin{array}{c}\mathbf{N} \text { of } \\
\text { Items }\end{array}$ \\
\hline .899 & .901 & 6 \\
\hline
\end{tabular}

Tabel 7. Hasil Uji Reliabilitas untuk Variabel 2 (Teknik)

\begin{tabular}{ccc}
\hline \multicolumn{3}{c}{ Reliability Statistics } \\
\hline $\begin{array}{c}\text { Cronbach's } \\
\text { Alpha }\end{array}$ & $\begin{array}{c}\text { Cronbach's Alpha Based } \\
\text { on Standardized Items }\end{array}$ & $\begin{array}{c}\text { N of } \\
\text { Items }\end{array}$ \\
\hline .788 & .801 & 2 \\
\hline
\end{tabular}

Tabel 8. Hasil Uji Reliabilitas untuk Variabel 3 (Dribble)

\begin{tabular}{|c|c|c|}
\hline \multicolumn{3}{|c|}{ Reliability Statistics } \\
\hline $\begin{array}{c}\text { Cronbach's } \\
\text { Alpha }\end{array}$ & $\begin{array}{c}\text { Cronbach's Alpha Based } \\
\text { on Standardized Items }\end{array}$ & $\begin{array}{l}N \text { of } \\
\text { Items }\end{array}$ \\
\hline .539 & .53 & 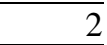 \\
\hline
\end{tabular}

Penelitian ini menemukan model struktural dan pengukuran kontribusi kondisi fisik dan teknik terhadap keterampilan meng-giring bola (dribbling). Model emperik yang ditemukan disajikan pada Gambar 1:

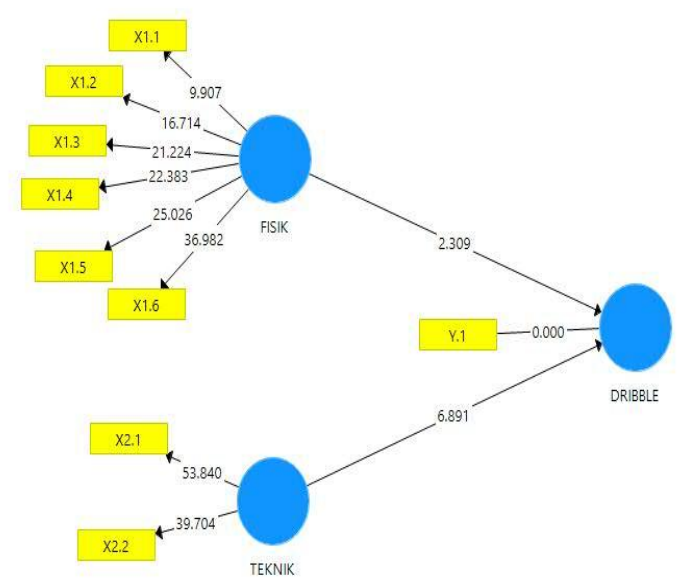

Gambar 1. Model struktural

Interpretasi model empirik berkaitan dengan model struktural disajikan oleh Tabel 9.

Tabel 9. Ringkasan Hasil Uji Hubungan antar Variabel Laten

\begin{tabular}{cccl}
\hline $\begin{array}{c}\text { Variabel } \\
\text { Laten }\end{array}$ & $\begin{array}{c}\text { Koefisien } \\
\text { Hubungan }\end{array}$ & t-Value & Kesimpulan \\
\hline $\begin{array}{c}\text { Fisik - } \\
\text { drible }\end{array}$ & $\gamma=0.210$ & $\begin{array}{c}2.309> \\
1.96(5 \%)\end{array}$ & Signifikan \\
$\begin{array}{c}\text { Teknik - } \\
\text { drible }\end{array}$ & $\gamma=0.550$ & $\begin{array}{c}6.991> \\
1.96(5 \%)\end{array}$ & Signifikan \\
\hline $\begin{array}{c}\text { Variabel } \\
\text { Laten }\end{array}$ & $\begin{array}{c}\text { Koefisien } \\
\text { Hubungan }\end{array}$ & t-Value & Kesimpulan \\
\hline $\begin{array}{c}\text { Fisik-drible } \\
\text { Teknik- } \\
\text { drible }\end{array}$ & $\gamma=0.210$ & $\begin{array}{c}2.309>1.96 \\
(5 \%)\end{array}$ & Signifikan \\
\hline
\end{tabular}

Tabel 9 menunjukkan bahwa (1) hubungan fisik dengan drible sebesar $\gamma=0.210$ dan nilai t hitung $=2.309$; dan (2) hubungan teknik dengan drible sebesar $\gamma=0.550$ dan nilai t hitung $=6.891$.

Temuan yang berkaitan dengan model pengukuran Bagian ini memaparkan temuan model pengukuran yang berkaitan dengan tiga variabel, yakni(1) fisik (2) teknik dan (3) dribble.

\section{Model Pengukuran Fisik}

Temuan model empirik berkaitan dengan model pengukuran fisik disajikan pada Tabel 10.

Tabel 10. Ringkasan hasil uji model pengukuran fisik 
Jurnal Keolahragaan 4 (2), September 2016 - 161

Chrissandy Yudha Pratama, Panggung Sutapa

\begin{tabular}{lllll}
\hline No & Variabel & Koefisien hubungan & t-value & Kesimpulan \\
\hline 1 & Daya tahan otot & 0.730 & $9.907>1,96$ & Valid \\
2 & Kelincahan & 0.757 & $16.714>1,96$ & Valid \\
3 & Kelentukan & 0.784 & $21.224>1,96$ & Valid \\
4 & Kecepatan & 0.854 & $22.383>1,96$ & Valid \\
5 & Keseimbangan & 0.869 & $25.026>1,96$ & Valid \\
6 & Power tungkai & 0.902 & $36.982>1,96$ & Valid \\
\hline
\end{tabular}

Tabel 10 menunjukkan bahwa daya tahan otot, kelincahan, kelentukan, kecepatan, keseimbangan dan power tungkai merupakan faktor penentu pengukuran fisik dinyatakan valid. Hal ini ditunjukkan oleh nilai t-hitung seluruh indikator $>1.96$.

\section{Model Pengukuran Teknik}

Temuan model empirik berkaitan dengan model pengukuran teknik disajikan pada Tabel 11.

Tabel 11. Ringkasan hasil uji model pengukuran teknik

\begin{tabular}{lllll}
\hline No & $\begin{array}{c}\text { Variabel } \\
\text { manifes }\end{array}$ & $\begin{array}{c}\text { Koefisien } \\
\text { hubungan }\end{array}$ & $\mathbf{t}$-value & Kesimpulan \\
\hline 1 & Persiapan & 0.919 & $\begin{array}{l}53.840> \\
1,96\end{array}$ & Valid \\
& & & $\begin{array}{l}39.704> \\
1,96\end{array}$ & Valid \\
\hline 2 & Pelaksanaan & 0.907 & & \\
& & &
\end{tabular}

Tabel 11 menunjukkan bahwa persiapan dan pelaksanaan merupakan faktor penentu teknik dinyatakan valid. Hal ini ditunjukkan oleh nilai t-hitung seluruh indikator $>1.96$.

\section{Model Pengukuran Dribbling}

Temuan model empirik berkaitan dengan model pengukuran sumber daya disajikan pada Tabel 12.

Tabel 12. Ringkasan hasil uji model pengukuran dribbling

\begin{tabular}{ccccc}
\hline No & $\begin{array}{c}\text { Variabel } \\
\text { manifes }\end{array}$ & $\begin{array}{c}\text { Koefisien } \\
\text { hubungan }\end{array}$ & Tvalue & Kesimpulan \\
\hline 1 & Dribble & 1.000 & - & $\begin{array}{l}\text { Valid } \\
\text { (interpolasi) }\end{array}$ \\
\hline
\end{tabular}

Tabel 12 menunjukkan bahwa tinggi dan rendah merupakan faktor penentu pengukur dribble dinyatakan valid. Hal ini ditunjukkan oleh nilai t-hitung seluruh indikator $>1.96$.

\section{Hasil Uji Hipotesis}

\section{Hipotesis Pertama}

Kontribusi faktor kondisi fisik terhadap keterampilan dribbling atlet bolabasket putri junior di Kabupaten Gunungkidul rendah. Hal ini dapat dilihat dari besar nilai pada Tabel 4.3 yaitu 0.210 , yang artinya faktor kondisi fisik pengaruh sebesar $21 \%$ terhadap keterampilan dribbling atlet bolabasket putri junior di Kabupaten Gunungkidul. Hal ini didukung juga dengan hasil t value sebesar 2.309 dimana hubungan dikatakan baik jika nilai dari t value nya lebih kecil dari 1.96 .

Hipotesis Kedua

Kontribusi faktor teknik terhadap keterampilan dribbling atlet bolabasket putri junior di Kabupaten Gunungkidul sangat tinggi. Hal ini dapat dilihat dari besar nilai pada tabel yaitu 0.550 , yang artinya faktor teknik memberi pengaruh sebesar $55 \%$ terhadap keterampilan dribbling atlet bolabasket putri junior di Kabupaten Gunungkidul sangat tinggi. Hal ini didukung juga dengan hasil $t$ value sebesar 6.891, dimana hubungan dikatakan baik jika nilai dari $\mathrm{t}$ value nya lebih besar dari 1.96.

\section{Hipotesis Ketiga}

Kontribusi kondisi fisik dan teknik terhadap keterampilan dribbling atlet bolabasket putri junior di Kabupaten Gunungkidul sedang. Hal ini dapat dilihat dari besar nilai pada tabel yaitu 0.455 yang artinya kondisi fisik dan teknik memberi pengaruh sebesar $45.5 \%$ terhadap dribbling atlet bolabasket putri junior di Kabupaten Gunungkidul. Hal ini didukung juga dengan hasil $t$ value sebesar 6.183, dimana hubungan dikatakan baik jika nilai dari t value nya lebih besar dari 1.96 .

\section{Pembahasan}

Pembahasan hasil pada penelitian ini berkaitan dengan; (1) indikator fisik terhadap faktor fisik; (2) indikator teknik terhadap faktor teknik; (3) pengaruh faktor fisik terhadap dribbling; (4) pengaruh faktor teknik terhadap dribbling; (5) pengaruh fisik dan teknik terhadap dribbling. Penjelasan dari faktor-faktor tersebut adalah sebagai berikut:

Indikator Fisik terhadap Faktor Fisik 


\section{Jurnal Keolahragaan 4 (2), September 2016 - 162 \\ Chrissandy Yudha Pratama, Panggung Sutapa}

Hasil penelitian menunjukan faktor fisik memiliki enam indikator yakni; (1) daya tahan otot lengan; (2) kelincahan; (3) kelentukan; (4) kecepatan; (5) keseimbangan; (6) power tungkai. Besar sumbangan indikator-indikator pada fisik dalam bermain basket dapat dilihat dari persamaan pengukuran dan matrik kovariannya. Ringkasan dapat dilihat pada Tabel 13:

Tabel 13. Ringkasan persamaan pengukuran faktor penentu fisik

\begin{tabular}{llll}
\hline No & Variabel & $\begin{array}{c}\text { Koefisien } \\
\text { hubungan }\end{array}$ & t -value \\
\hline 1 & Daya tahan otot & 0.730 & $9.907>1,96$ \\
2 & Kelincahan & 0.757 & $16.714>1,96$ \\
3 & Kelentukan & 0.784 & $21.224>1,96$ \\
4 & Kecepatan & 0.854 & $22.383>1,96$ \\
5 & Keseimbangan & 0.869 & $25.026>1,96$ \\
6 & Power tungkai & 0.902 & $36.982>1,96$ \\
\hline
\end{tabular}

Tabel 13 menunjukan nilai parameter pada persamaan pengukurannya setiap indicator. Pembahasannya sebagai berikut:

\section{Daya Tahan Otot Lengan}

Harga koefisien hubungan sebesar 0.730 menunjukan bahwa dayatahan otot lengan dapat menjelaskan varian fisik secara memadai. Harga koefisien hubungan 0.730 yang berarti daya tahan otot lengan dapat memberi sumbangan kepada fisik sebesar 73\%. Hal ini dibuktikan oleh nilai t > 1.96

\section{Kelincahan}

Harga koefisien hubungan 0.757 menunjukan bahwa kelincahan dapat menjelaskan varian fisik secara memadai. Harga koefisien hubungan 0.757 yang berarti kelincahan dapat memberi sumbangan kepada fisik sebesar $75.6 \%$. Hal ini dibuktikan oleh nilai $\mathrm{t}>1.96$.

\section{Kelentukan}

Harga koefisien hubungan 0.784 menunjukan bahwa kelentukan dapat menjelaskan varian fisik secara memadai. Harga koefisien hubungan 0.784 yang berarti kelentukan dapat memberi sumbangan kepada fisik sebesar $78.4 \%$. Hal ini dibuktikan oleh nilai $\mathrm{t}>1.96$.

\section{Kecepatan}

Harga koefisien hubungan 0.854 menunjukan bahwa kecepatan dapat menjelaskan varian fisik secara memadai. Harga koefisien hubungan 0.854 yang berarti kecepatandapat memberi sumbangan kepada fisik sebesar $85.4 \%$. Hal ini dibuktikan oleh nilai $\mathrm{t}>1.96$.

\section{Keseimbangan}

Harga koefisien hubungan 0.869 menunjukan bahwa keseimbangan dapat menjelaskan varian fisik secara memadai. Harga koefisien hubungan 0.869 yang berarti keseimbangan dapat memberi sumbangan kepada fisik sebesar 86.9\%. Hal ini dibuktikan oleh nilai $\mathrm{t}>1.96$.

\section{Power Tungkai}

Harga koefisien hubungan 0.902 menunjukan bahwa power tungkai dapat menjelaskan varian fisik secara memadai. Harga koefisien hubungan 0.902 yang berarti power tungkai dapat memberi sumbangan kepada fisik sebesar $90.2 \%$. Hal ini dibuktikan oleh nilai t > 1.96.

Indikator Teknik terhadap Faktor Teknik

Hasil penelitian menunjukan faktor teknik memiliki dua indikator; (1) fase persiapan; (2) fase pelaksanaan. Besar sumbangan indikator-indikator pada teknik bermain basket dapat dilihat dari nilai koefisien hubungannya. Ringkasan dapat dilihat pada Tabel 14:

Tabel 14. Ringkasan persamaan pengukuran faktor teknik

\begin{tabular}{llll}
\hline No & $\begin{array}{c}\text { Variabel } \\
\text { manifes }\end{array}$ & $\begin{array}{c}\text { Koefisien } \\
\text { hubungan }\end{array}$ & t -value \\
\hline 1 & Persiapan & 0.919 & $53.840>1,96$ \\
2 & Pelaksanaan & 0.907 & $39.704>1,96$ \\
\hline
\end{tabular}

Fase Persiapan

Harga koefisien hubungan 0.919 menunjukan bahwa fase persiapan dapat menjelaskan varian teknik secara memadai. Harga koefisien hubungan 0.919 yang berarti power fase persiapan tungkai dapat memberi sumbangan kepada teknik sebesar 91.9\%. Hal ini dibuktikan oleh nilai $\mathrm{t}>1.96$.

Fase Pelaksanaan

Harga koefisien hubungan 0.907 menunjukan bahwa fase pelaksanaan dapat menjelaskan varian teknik secara memadai. Harga koefisien hubungan 0.907 yang berarti fase pelaksanaan dapat memberi sumbangan kepada teknik sebesar $90.7 \%$. Hal ini dibuktikan oleh nilai $\mathrm{t}>1.96$.

\section{Hubungan Fisik terhadap Dribbling}

Hasil analisis menunjukan bahwa ada hubungan positif dan signifikan antara fisik terhadap dribbling. Hasil analisis data dapat dilihat pada lampiran. Berdasarkan hasil analisis menggunakan SMART PLS bahwa hu- 


\section{Jurnal Keolahragaan 4 (2), September 2016 - 163 \\ Chrissandy Yudha Pratama, Panggung Sutapa}

bungan fisik terhadap dribbling sebesar 0.210, yang artinya fisik memberikan pengaruh $21 \%$ terhadap dribbling.

Hubungan Teknik terhadap Dribbling

Hasil analisis menunjukan bahwa ada hubungan positif dan signifikan antara teknik terhadap dribbling. Hasil analisis data dapat dilihat pada lampiran. Berdasarkan hasil analisis menggunakan SMART PLS bahwa hubungan teknik terhadap dribbling sebesar 0.550, yang artinya teknik memberikan pengaruh $55 \%$ terhadap dribbling .

Hubungan Fisik dan Teknik terhadap Dribbling

Hasil analisis menunjukan bahwa ada hubungan positif dan signifikan antara fisik dan teknik terhadap dribbling. Hasil analisis data dapat dilihat pada lampiran. Berdasarkan hasil analisis menggunakan SMART PLS bahwa hubungan fisik dan teknik terhadap dribbling sebesar 0.455 , yang artinya fisik dan teknik memberikan pengaruh $45.5 \%$ terhadap dribbling.

\section{SIMPULAN}

Berdasarkan hasil penelitian dan pembahasan, ada tiga kesimpulan penelitian. Ketiga tersebut disajikan berikut ini: (1) terdapat kontribusi faktor kondisi fisik terhadap keterampilan dribbling atlet bolabasket putri junior di Kabupaten Gunungkidul, (2) terdapat kontribusi faktor teknik terhadap keterampilan dribbling atlet bolabasket putri junior di Kabupaten Gunungkidul sedang, (3) terdapat kontribusi kondisi fisik dan teknik terhadap dribbling atlet bolabasket putri junior di Kabupaten Gunungkidul sedang.

\section{DAFTAR PUSTAKA}

Ahmadi, N. (2007). Permainan bolabasket. Solo: Era Intermedia

Bompa, T., \& Haff, G.G. (2009). Sport psychology. Springfield: Blackwell Publishing.

Fresno, D. B., Sanchez, A. J. L., Rave, J. M. G. (2012). Fitness level and body composition of elite female players in england basketball league division i. International Journal of Sport and Exercise Science, 4(2): 15-24.Diambil pada tanggal 18 Februari 2016, dari http://web.nchu.edu.tw/ biosimulation/ journal/pdf/vol-4-no02/vol-4-no-2-b0001.pdf

Ghazali, I. (2012). Partial least squares konsep, teknik, dan aplikasi. Semarang: BP Universitas Diponegoro.

James, J. D. \& Ridinger, L. L. (Sep 2002). Journal of sport behavior, 25.3, 260278. Diambil pada tanggal 18 Februari 2016 , dari http://search.proquest.com/openview/74 4fdd33496007d4e83a7382bf3da182/1? pq-origsite $=$ gscholar

Jonker, J P, B. \& Wahyuni, S. (2011). Metodologi penelitian: panduan untuk master dan Ph D. di bidang menejemen. Jakarta: Salemba Empat.

Martinez J. A. \& Martinez L. (2011).A stakeholder assessment of basketball player evaluation metrics.J. Hum. Sport Exerc. Vol. 6, No. 1, pp. 153-183. Diambil pada tanggal 18 Februari 2016, dari

http://rua.ua.es/dspace/bitstream/10045/ 16880/1/JHSE_6_1_17.pdf

Montgomery, P., Pyne, D. B., Minahan, C. L. (2010). The physical and physiological demands of basketball training and competition. International Journal of Sports Physiology and Performance, Vol. 5(1), pp. 75-86.

Nurhidayah, N., \& Sukoco, P. (2015). Pengaruh model latihan dan koordinasi terhadap keterampilan siswi ekstrakurikuler bola basket SMPN I BANTUL. Jurnal Keolahragaan, $3(1), \quad 66$ - 78. doi:http://dx.doi.org/10.21831/jk.v3i1.4 $\underline{970}$

Oliver, J. (2007). Dasar-dasar bolabasket. Bandung: PT Intan Sejati

Prusak, K. A. (2007). Permainan bolabasket. Klaten: PT Intan Sejati

Sukadiyanto.(2005). Pengantar teori dan metodologi melatih fisik.Yogyakarta: FIK UNY.

Yamin, S \& Kurniawan, H. (2011). Generasi baru mengolah data penelitian dengan partial least square path modeling. Jakarta Selatan: Salemba Infotek. 